\title{
A DESCRIPTION AND CLASSIFICATION OF THE COMMON DISORDERS OF SPEECH IN CHILDREN
}

BY

\author{
T. T. S. INGRAM \\ From the Department of Child Life and Health, University of Edinburgh and the Royal Hospital for Sick Children, \\ Edinburgh
}

(RECEIVED FOR PUBLICATION MARCH 9, 1959)

The full assessment of children suffering from speech defects requires a team consisting of speech therapist, paediatrician, psychologist and otologist. The additional services of a phonetician, neurologist, orthodontist, plastic surgeon, radiologist, social worker or psychiatric social worker and child psychiatrist are often helpful.

Unfortunately the majority of descriptions and classifications of speech disorders in childhood are by speech therapists working without much medical co-operation and advice. With honourable exceptions, they tend to regard speech disorders as rather isolated phenomena, dissociated from the other behavioural and psychological characteristics of the child. In the present paper an attempt is made to describe and classify the disorders of speech most frequently encountered in a hospital speech clinic from the point of view of the paediatrician of a diagnostic team.

\section{Case Material and Methods of Examination}

The descriptions of speech disorders are based largely on experience in the Speech Clinic of the Royal Hospital for Sick Children, Edinburgh, in the last three years. During this time a total of 348 patients were referred, though for various reasons it was possible to investigate only 189 of them fully. The patients are not representative of an unselected sample of children in the community as judged by the figures for all live births given by the Registrar General for Scotland (1951). There is an excess of patients in Social Classes I and II, possibly because of the greater attention paid to speech defects in these classes (Table 1). The greater excess of patients in Social Classes I and II over the age of 5 than under the age of 5 is probably the result of the fact that children in the lower social classes attend corporation schools where there is a very comprehensive speech therapy service. In private fee-paying schools, where more attention is usually paid to speech defects, speech therapy is rarely provided. Children with speech defects attending these schools were frequently referred to the Speech Clinic in the Hospital.

Detailed family, birth and developmental histories were taken, with particular emphasis on the rate, and any abnormalities, of speech development. The children were subjected to a detailed paediatric and neurological examination, and behaviour in play was observed for as long as possible in each case. The child's speech was studied jointly by the paediatrician and the speech therapist, and detailed notes were made of its intelligibility and of the particular defects which were observed. In many cases tape recordings were made, though it is always easier, in fact, to examine speech for defects of articulation in the presence of the patient. Speech was studied from the points of view of level of language ability and defects of articulation.

Attempts were made to assess the child's ability to understand what was said to him by his parents

TABLE 1

DISTRIBUTION OF 189 PATIENTS WITH SPEECH DISORDERS BY AGE AND SOCIAL CLASS

\begin{tabular}{|c|c|c|c|c|c|c|}
\hline \multirow{2}{*}{ Age } & \multicolumn{5}{|c|}{ Social Class } & \multirow{2}{*}{ Total } \\
\hline & I & II & III & IV & v & \\
\hline $\begin{array}{ll}\text { Under } 3 & . . \\
3-5 & . \\
5-10 & . \\
10+ & .\end{array}$ & $\begin{array}{r}1 \\
25 \\
12 \\
3\end{array}$ & $\begin{array}{r}1 \\
16 \\
11 \\
3\end{array}$ & $\begin{array}{r}10 \\
48 \\
20 \\
3\end{array}$ & $\begin{array}{r}2 \\
13 \\
5 \\
2\end{array}$ & $\begin{array}{l}1 \\
9 \\
2 \\
2\end{array}$ & $\begin{array}{r}15 \\
111 \\
50 \\
13\end{array}$ \\
\hline All ages & 41 & 31 & 81 & 22 & 14 & 189 \\
\hline $\begin{array}{l}\text { Under } 5 \ldots \\
\text { Over } 5\end{array}$ & \multicolumn{2}{|c|}{$\begin{array}{l}43 \\
29\end{array}$} & $\begin{array}{l}58 \\
23\end{array}$ & \multicolumn{2}{|c|}{$\begin{array}{l}25 \\
11\end{array}$} & $\begin{array}{r}126 \\
63\end{array}$ \\
\hline All ages .. & \multicolumn{2}{|c|}{72} & 81 & \multicolumn{2}{|c|}{36} & 189 \\
\hline Approx. $\%$ & \multicolumn{2}{|c|}{39} & 42 & \multicolumn{2}{|c|}{19} & 100 \\
\hline $\begin{array}{l}\text { Registrar } \\
\text { General } \\
\text { Scottand } \\
1951 \%\end{array}$ & \multicolumn{2}{|c|}{$12 \cdot 5$} & $58 \cdot 3$ & \multicolumn{2}{|c|}{$29 \cdot 2$} & 100 \\
\hline
\end{tabular}


and by other people. Any apparent tendency for the child to rely unduly on gesture, or on watching people talking to him, was noted. Rough tests of hearing were used during the general examination of the patient, his responses to whistles of various pitches, bells, the rustling of paper, vibration forks, whispering, talking and shouting being observed. Full audiometry was performed on all children as soon as they were co-operative enough for this examination to be performed. Handedness was tested rather unscientifically by noting the hand which the child used in each of four performance tests carried out three times. Each patient was asked to turn a door handle, break a stick, throw and catch a ball. Patients not using a single hand for nine or more of the total of 12 tests were classified as being ambidextrous. Eyedness and footedness were also tested (Ingram and Reid, 1956).

A psychiatric social worker, seconded to the Clinic, was asked to investigate the home situation of 41 patients in whom psychological stress appeared to be important. Thirty-one patients were further assessed in the Department of Psychological Medicine. The opinion of an otolaryngologist was asked in 34 cases, of a plastic surgeon in five, and of an orthodontist in eight. Eleven patients were admitted to hospital on account of physical conditions noted at the time of assessment. These included patients suffering from cretinism, epilepsy, enuresis, phenylketonuria, fibrocystic disease of the pancreas and Sjøgren's syndrome.

\section{Classification}

The classification is by clinical findings. Categories are defined in the first place by the form of the major speech defect. Thus distinctions are made between disorders affecting the voice predominantly (dysphonia), those whose main effect is to alter the rhythm of speech (dysrhythmia) and those in which abnormalities of articulation are the presenting feature.

It must be admitted that classification on the basis of the major defect of speech is somewhat arbitrary and crude (as are most classifications), and it is necessary to ignore a number of significant clinical findings in many cases for the purpose of giving the speech condition a name. For example, many patients suffering from a stammer will have minor abnormalities of articulation; some patients with 'specific developmental speech disorders' will have minor stammer (speech dysrhythmia). It is impossible to take account of these subsidiary defects in the major categories.

Further classification is by associated clinical findings. When direct interference with the function of the articulatory organs can be demonstrated the disorder is considered to be 'dysarthric'. When the abnormalities of articulation are part of a more general disorder and no direct interference with the function of the articulatory organs can be demonstrated they are considered to be 'secondary'. When disorders apparently confined only to the functions of speech are present, unassociated with direct interference with the articulatory organs, they are classified as 'specific developmental' or 'functional speech disorders' (Table 2).

TABLE 2 CLASSIFICATION OF $\begin{aligned} & \text { SPEECH DISORDERS FOUND IN } \\ & 189 \text { CHILDREN }\end{aligned}$

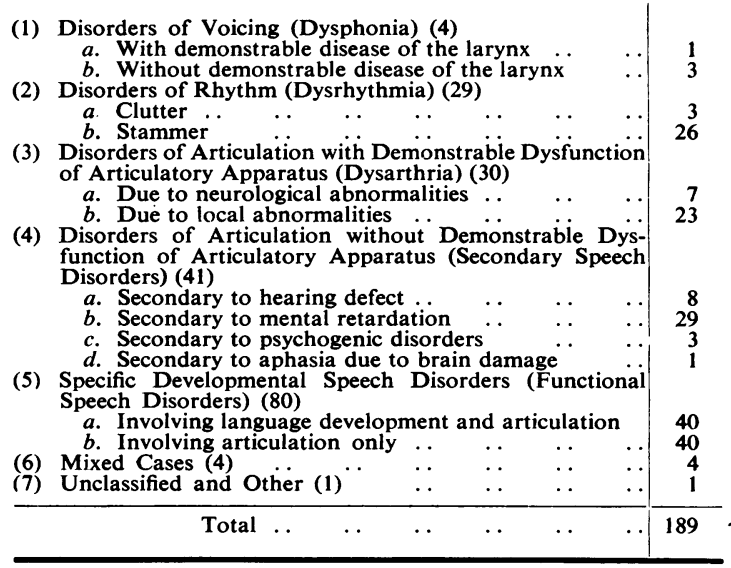

In some cases there are contributory causal factors in the speech disorder. For example, a child with brain damage secondary to encephalitis or trauma may have a disorder of articulation which is partly secondary to aphasia and partly the result of inco-ordination of the organs of articulation. Such patients may conveniently be placed in the category of 'mixed cases'. They are relatively few.

\section{Categories}

Disorders of Voicing. Disorders of voicing are relatively uncommon in childhood, amounting to no more than $4 \%$ in most large series of patients with speech defects. In the present series there were four patients with disorders of the voice (approximately $2 \%$ of the series).

The only disorder of voicing considered in the present classification is chronic lack of voice, which makes the child sound as if he is hoarse. This is similar in quality to the "loss of voice" suffered by adults with laryngitis. It must be distinguished from the effects of excessive nasal escape (hyperrhinophonia) or nasal obstruction (hyporhinophonia). In 
these conditions difficulty of articulation is the striking abnormality. They have therefore been included under the heading of 'dysarthria'.

Dysphonia affects girls rather more frequently than boys, or at any rate is complained of more frequently by the parents of girls. It may occur at any age and has been observed in a child of 6 months, but more commonly it begins between the ages of 2 and 8 years. Its onset is commonly gradual. Often there is a period of weeks or months during which the condition is intermittent, being present for a day or two at a time and then recovering. Even when finally established, the severity of dysphonia varies from week to week, from day to day and even from hour to hour. Frequently the child is able to shout, and sometimes to sing, but not to speak with normal voice.

A number of inflammatory, traumatic and neoplastic laryngeal conditions interfering with the function of the vocal cords may cause dysphonia in childhood. I have seen it personally following traumatic laryngoscopy and inhalation of caustic, complicating chronic bronchitis and laryngitis, associated with nodules of the vocal cords and papillomata of the larynx, and occurring in the course of Sjøgren's syndrome (Birrell, 1954).

In many cases, however, no abnormalities of the larynx can be found. The immediate assumption is commonly made that the dysphonia is therefore of 'psychological origin'. It seems to be equally likely that there are abnormalities of the vocal cords in these patients, which cannot be recognized by our present crude methods of investigation.

There are no well recognized methods of treating dysphonia in childhood by 'speech therapy'. Rest of the voice for a period of four to six weeks will often result in a marked improvement in voicing. Unfortunately this is often transient, and relapse occurs as soon as the child begins to shout again. A proportion of children with dysphonia, more boys than girls, show improvement at the time of adolescence, whether the larynx is obviously abnormal or not. Such improvement is impossible to predict, however, and many patients continue to have abnormalities of voicing into adult life.

Speech Dysrhythmias. Involuntary interference with the normal rhythm of speech is one of the commonest disorders of speech in childhood. Two main types may be recognized.

Clutter consists of a more or less sudden irregular acceleration of speech which results in a shift of stress and syllable division in speech. The words sound 'run into one another' and sometimes speech may be so disturbed as to be incomprehensible.
Many children aged between 2 and 4 years may show clutter transiently for a period of weeks or months without any associated or subsequent abnormality of speech. When clutter occurs after the age of 5 it is more often associated with stammer or hesitation (Van Riper, 1947).

Involuntary temporary arrest of the flow of speech may be manifest as hesitation, a transient inability to produce the next expected syllable resulting in a period of no speech. Stammer consists of the involuntary repetition of a sound as well as an inability to move beyond it. It is unrewarding to distinguish too cleverly between hesitation and stammer. They are often associated. Many patients' dysrhythmia first takes the form of hesitation, and months or years later they begin to stammer. Others stammer first and then show hesitation.

Hesitation or stammer is found more often in children whose fathers are in Social Classes I and II (Registrar General) than in the lower social classes. There appears to be no difference in the observed and expected birth order of patients. Males are more frequently affected than females, the ratio being as high as four to one in some series (Wilson, 1954). In the family history a high proportion of relatives stammer, $44 \%$ according to Johnson, Brown, Curtis, Edney and Keaster (1948). There is a higher proportion of ambidexterity and left-handedness amongst relatives than expected (Travis, 1931). Of the present small series of 29 patients, $38 \%$ had parents or siblings with speech defects. These were dysrhythmic in type except in one instance. The parents and/or siblings of $27 \%$ were left-handed or ambidextrous.

The birth history and motor milestones of patients tend to be within normal limits. Speech development is not significantly retarded. The majority of children are of average intelligence or better, and show no neurological defects.

A relatively high proportion of patients will be found to be left-handed or ambidextrous, the proportion depending largely on the methods of testing used (Orton, 1937; Morley, 1957). In the present series, 12 of the 29 patients were found to show little laterality of handedness, and one was sinistral.

A high proportion of patients show abnormalities of behaviour. These were present in 21 of the 29 patients studied in this series. They included temper tantrums in four, excessive dependence in five, excessive excitability or tearfulness in five, night terrors in four, enuresis in three and habit spasms in three. Nine of the patients were disturbed enough to merit psychiatric treatment. The extent to which the speech dysrhythmia is an aetiological factor in causing anxiety symptoms is probably over- 
estimated. In many cases symptoms of abnormal behaviour preceded the appearance of the speech defect, and both could be related to the same emotional stresses. Parents related the onset of symptoms to maternal separation before the age of 4 years in five instances (the child being hospitalized in three), to physical accidents in two, to severe whooping cough in two and to crippling accidents to the father in two.

The modes of onset and course of dysrhythmia in childhood are relatively consistent. The majority of cases of uncomplicated clutter recover normal speech before they are 5 years of age. Hesitation or stammering appears in most persistent stammerers for the first time between the ages of 2 and 4 years. In only five of 25 patients with stammer or hesitation in this series did symptoms appear after 5 years of age. It is difficult to know how many children showing definite persistent stammering at this period recover completely and how many later have dysrhythmic speech symptoms. Of children who present with persistent stammer, two-thirds (17 of 25 in this series) have never been really free of the symptoms for more than four weeks at most from the time of its onset.

True remissions of stammer lasting for more than six months are more frequent in those where first symptoms occur under the age of 5 years, but the statement made in text-books that a stammer occurring in a pre-school child is likely to be of little significance. requires qualification. Of the eight remissions of stammer which occurred in this series, all but one of them occurred before the age of 5 years. Only three of the remissions lasted longer than three years. The remaining five patients began to stammer again shortly after going to school. It is too early to know if the other three remissions are permanent or not.

The subsequent course of stammer varied greatly according to the reaction of the patient to his symptom. Some children adjusted to quite a severe dysrhythmia and were surprisingly undisturbed by its presence. Others began to avoid speaking and making social contact whenever possible. They attempted to avoid words on which they believed they would stammer, and restricted their activities in an attempt to hide their speech defect. In time the fear of stammering may become the most potent cause of stammer.

It is extremely doubtful if speech therapy per se is helpful in speech dysrhythmia. A mother confessor or a child psychiatrist (either of which roles speech therapists may be found adopting) occasionally seems to benefit the patient's attitude to his speech defect. There appear to be no reliable comparative figures on which to base conclusions about the proportion of patients with stammer who spontaneously improve at adolescence or in early adult life with the help of, in spite of, or without speech therapy.

My clinical impression is that patients in whom it has taken very severe emotional stresses to precipitate stammering tend to have a better prognosis than those who stammered without much evident emotional stress being necessary. This impression, like so many concerning speech disorders, requires confirmation.

Dysarthric Speech Disorders. In this category are included those disorders of articulation which are the result of organic disease causing interference with or failure of the normal mechanical functions of part or parts of the articulatory apparatus. Thirty-one of the 189 patients were in this category.

The category is divided into two sub-categories. Patients whose articulatory difficulties are due to neurological abnormalities are included in the first. In these there is rarely much deformity of the articulatory organs themselves. In the second are those disorders of articulation which are the result of local abnormalities affecting the articulatory apparatus. Deformity of the articulatory organs may often be observed.

In general, speech defects in this category are characterized by their consistency. They vary relatively little from day to day or from hour to hour, and the same sounds as are abnormal during spontaneous speech are found on testing to be defective. For example, the sounds requiring nasopharyngeal closure will be consistently defective in patients with cleft palate.

Apart from the six patients with cerebral palsy, motor milestones were within normal limits, and only one of the other 24 patients had retarded language development, though in many cases it was a long time before people outside their immediate families could understand what the children said. Three of the six patients with cerebral palsy failed to walk without support before 18 months, and all of them failed to say recognizable first words by 18 months and phrases by 30 months (Table 3). Again with the exception of those patients with cerebral palsy, the children in this category appeared to be of average intelligence. A relatively high proportion, 14 of the 30 patients, suffered from abnormalities of behaviour, however. In five cases there was immaturity of behaviour, manifest as excessive attachment to the mother, inability to play with other children of similar age, inability to accept a school situation at the normal age or play 
TABLE 3

WALKING AND SPEECH DEVELOPMENT OF 30 CHILDREN WITH DEMONSTRABLE DYSFUNCTION OF ARTICULATORY APPARATUS (DYSARTHRIA)

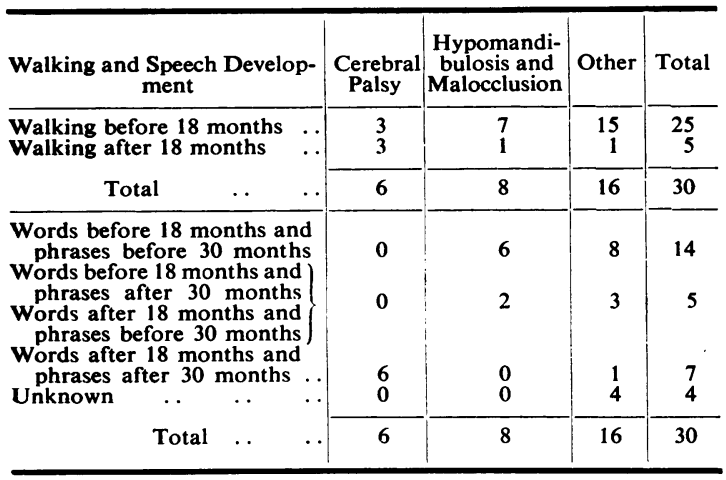

characteristic of a younger age level. Enuresis was present in six patients, thumb or hand sucking in three. Three patients were excessively tearful, fearful, or unusually withdrawn. Three patients showed a characteristic form of overactive behaviour often found in children with cerebral damage, especially when it affects the temporal lobe (Ingram, 1956). The extent to which these abnormalities of behaviour could be regarded as other symptoms of the underlying disturbance which was responsible for the speech defect, and how much they were the result directly and indirectly of the speech defect, is extremely difficult to assess.

The neurological lesions in this category are conveniently divided into those affecting the brain, those affecting the brain stem and those affecting the lower motor neurone (Table 4). Cerebral palsy

TABLE 4

CLASSIFICATION INTO SUB-CATEGORIES OF 30 PATIENTS SUFFERING FROM DISORDERS OF ARTICULATION WITH DEMONSTRABLE DYSFUNCTION OF ARTICULATORY APPARATUS (DYSARTHRIA)

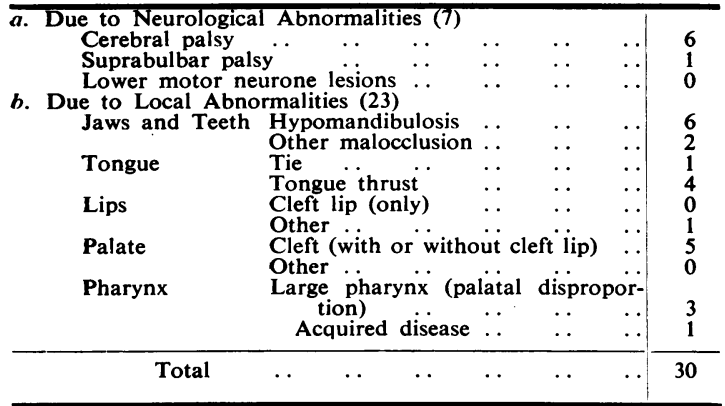

is by far the commonest cause of neurological lesions, but it is worth emphasizing that dysarthria is not the commonest form of speech defect in cerebral palsy. Though dysarthria is relatively frequently found in severe dip.egia, severe ataxia, dyskinesia and bilateral hemiplegia, it is uncommon in mild diplegia (especially paraplegia) and hemiplegia. In the latter disorders defective speech is more frequently part of a general retardation of development, or is secondary to aphasia. In patients with dyskinesia following kernikterus, abnormalities of articulation are commonly the result of a combination of articulatory inco-ordination and hearing defect.

Suprabulbar paresis (facial diplegia, Moebius' syndrome) is easily recognized when it is severe and especially when it affects eye movements (Henderson, 1939; Evans, 1955). Minor manifestations of the condition may be more difficult to recognize, however, and a number of patients have been observed in whom poor voluntary movements of the lips, tongue and soft palate were present without obvious voluntary paralysis of these organs. The trained phonetician can be of great help in the accurate diagnosis of these disorders by his interpretations of the child's speech in terms of tongue, lip and palatal movements.

Though no cases occurred in the present series, lower motor neurone lesions affecting articulation have been seen occasionally following poliomyelitis and diphtheria, but they are more commonly the result of peripheral nerve damage during tonsillectomy. The history in patients who have suffered damage to a palatal nerve is typical. Following discharge from hospital the speech is noted to be abnormal and fluids may come down the nose when the child tries to drink. Though the ability to drink is recovered after a few weeks the child continues to speak 'down the nose', and defects of the plosives, vowels and ' $s$ ' ' $\theta$ ' and ' $\int$ ' sounds are noted.

Since a single local abnormality of the mouth or pharynx may affect a number of the organs of articulation it is more convenient to classify dysarthric speech disorders by the nature of the abnormality rather than by the type of speech defect which they cause. Thus whilst hypomandibulosis prevents correct dental occlusion and sometimes apposition of the lips, involuntary protrusion of the tongue during speech, 'tongue thrust', is often a more important cause of disordered articulation.

Other forms of malocclusion and dental abnormalities cause abnormalities of articulation less frequently than hypomandibulosis. The commonest of them are the result of an undue prominence of the lower jaw, associated with open bite, wide separation of the incisors, or missing teeth. These conditions are most frequently associated with 'lisping' due to the lateral or central protrusion 
of the tongue between the teeth when sibilants are produced.

In a few children the wide separation or anterior protrusion of the upper incisors appears to be attributable to excessive finger or thumb sucking. In others there is associated 'tongue thrust', though the extent to which this can be regarded by itself as the cause of dental abnormalities must remain in doubt.

Tongue tie is an uncommon cause of articulatory difficulties, though it is often blamed for them. A commoner abnormality of the function of the tongue which does cause articulatory difficulties is 'tongue thrust'. This condition may be associated with cerebral palsy or congenital abnormalities of the mouth, as have been described. It is often found in association with chronic tonsillitis and adenoiditis. But it may be present as the only obvious abnormality in many cases. In children showing it the pattern of swallowing is often observed to be immature in type and on stroking the lips gently a mild sucking reflex associated with opening of the mouth and some tongue protrusion is not infrequently observed (Francis, 1958). Abnormalities of the lips alone are not a common cause of articulatory difficulty, though one case occurred in the present series in which the upper lip was abnormally high and fixed.

Malformations of the palate are relatively frequent causes of severe articulatory difficulties. The commonest malformation is an actual cleft in the soft palate. Less commonly a midline defect in the muscular elements without a defect in the mucous membrane (submucous cleft palate) may be diagnosed if the cleft palate is gently palpated. The articulatory defect is similar in type, though less severe than that found in a true cleft palate.

The excessive nasal escape which results when the palate is cleft impairs all vowel and consonant sounds, with the exception of ' $m$ ', ' $n$ ' and ' $n$ ' in which considerable nasal outflow of air is usually required. Substitutions for particularly defective sounds are frequent. For example glottal stops may replace plosives. Associated abnormalities also contribute to the speech defect. Especially in children with bilateral clefts of the palate there is frequently marked deformity of the alveolar bony structure, especially after operation, and dental malocclusion results. The upper lip is all too often rather functionless (Morley, 1954).

A relatively small number of patients present with 'cleft palate speech' with nasal escape, in whom no abnormalities of palatal movement can be found. In the majority speech has been 'through the nose' from the earliest years, and in a few there is a history of escape of fluids through the nose when drinking in infancy. In others a change from normal speech has been noted following adenoidectomy. On examination many of these patients show marked anterior prominence of the maxillary bones and the pharynx appears to be unusually deep, so that the length of the palate is inadequate for its posterior margin to reach the posterior nasopharyngeal wall. Radiological investigation will often confirm that the pharynx is, in fact, abnormally deep and the palate inadequate in size, in spite of full movement, to close the nasopharynx. Many of these patients can be helped by operations designed to reduce the size of the pharyngeal aperture (Calnan, 1957; Gibb, 1958). In a few patients nasal escape appears to be due to impaired palatal movement, the result of inflammatory peri-tonsillar induration, or scarring following tonsillectomy.

Tonsillitis and enlargement of the adenoids are much less common single causes of significant persistent dysarthria in childhood than is often stated. In the present series only one patient was included in the sub-category of dysarthria due to 'acquired disease of the pharynx'.

Secondary Speech Disorders. These are disorders of articulation which are not due to direct interference with the mechanics of the articulatory organs, but are secondary to other physical, mental or psychiatric conditions. Often it may be demonstrated that these organs can be moved normally, and frequently that sounds not used in spontaneous speech can in fact be produced by the child. The most important causes of articulatory disorders of this type are hearing defects and mental retardation.

Children with hearing defects have never heard or have ceased to hear speech sounds correctly, and therefore cannot be expected to reproduce them in speech. A study of the behaviour and articulatory abnormalities shown by the child will often give a clue to the type of hearing defect. Children with some loss of hearing for high tones only will commonly show failure in articulating ' $f$ ' ' $\Theta$ ', ' $p$ ', ' $t$ ', ' $\int$ ' and 's'. Children with more severe hearing loss for all frequencies will often only produce sounds requiring much lip movement, which they can see when they watch people talking to them. This is not always the case, however, and a number of patients have been seen with retarded speech development and poor performance on intelligence tests whose hearing was found to be significantly defective on audiometry, to the surprise of the examiner. Once they have learnt how to use a suitable hearing aid the children have often improved markedly in their performance on intelligence tests. This emphasizes the need for routine audiometry in all children with speech defects. 
Children with mental retardation present more complex disturbances of articulation. Often there appears to be a failure to perceive and discriminate speech sounds accurately, possibly because of a reduced span of attention. Even when 'parrotting' what has just been said to them, their articulation will often be quite inaccurate. Speech development is usually considerably retarded, and the patients show errors of articulation commonly found in much younger normal children. In these patients the later acquired sounds are usually abnormal, especially ' $r$ ', ' $\Theta$ ', ' $\int$ ', ' $t$ ' ' and ' $d 3$ '.

Defects of articulation are often inconsistent and vary from sentence to sentence of spontaneous speech. There may also be language disorder with the omission of small words, especially prepositions, auxiliary verbs and conjunctions. There may be a general innaccuracy in the articulation of practically all speech sounds, which almost justifies the loose description of 'clumsy speech' which is often given by the parents of these patients. There is often a failure to develop normal patterns of intonation and stress, so that speech is curiously monotonous.

Whilst in aphasia the defect of language is (by definition) the most important cause of interference with speech, the importance of articulatory abnormalities has been rather under-estimated (Critchley, 1952). Especially in children whose cerebral damage has been sustained before speech development has been completed, there is often gross disturbance of the ability to articulate words and their component individual syllables correctly. In many cases it is difficult to draw a line between the language difficulties and difficulties in articulation; omission of small words, conjunctions, prepositions, auxiliary verbs and pronouns may be associated with the omission of syllables, especially the terminal parts of words; reversals and confusion of word order may be associated with reversals and the confusion of the order of syllables in individual words and in the distortion and mispronunciation of syllables which are spoken. There may also be quite bizarre alterations of rhythm and stress, making the patient sound as if he were speaking a foreign language rather well, as in a case of Monrad-Krohn (1947).

As might be expected, the milestones of motor and speech development were very retarded amongst patients in the category of 'secondary speech disorders', largely due to the high proportion of mentally retarded patients. Major and minor physical abnormalities were relatively common. Epilepsy was present in six cases. Hyperteleorism, syndactyly, hypospadias, congenital heart disease and hemiplegia were each observed in two patients.
There was one untreated cretin amongst the mentally retarded patients.

Behaviour abnormalities were also common, occurring in 31 of the 41 patients. Twenty-two children were described as being excessively dependent or immature by their parents. Three were over-active and showed the typical behaviour shown by some brain-damaged children described by Ounsted (1955) and Ingram (1956). In two cases behaviour was classified as autistic by child psychiatrists.

Specific Developmental Speech Disorders ('Functional Speech Disorders'). In this category are placed those patients who show disorders of articulation from the time they first attempt formed speech, and in which the speech disorder is neither associated with obvious abnormalities of articulatory function, nor secondary to demonstrable disease. Eighty of the 189 patients who were fully examined were placed in this category.

Patients in this category are characterized by the unexpectedly slow development of intelligible speech, though their milestones of motor development are usually within normal limits and their intelligence is within average limits, or not sufficiently impaired to account for the degree of retardation of speech development. This is shown in Table 5 in which it will be observed that 49 , or $61.25 \%$, of the 80 patients said their first recognizable words (excepting Mum, Mam, Mama, Da, Dad, Dada) after the age of 18 months and first joined words together after the age of 30 months. Fifteen, or almost $19 \%$, did not say their first words until after 30 months and phrases until 42 months or later. Yet, in spite of its slow development, speech is almost invariably perfectly intelligible by the age of 7 or 8 years in these patients.

Of the 80 patients in this category 58 were boys and 22 were girls, giving a male to female sex ratio which is comparable to other hospital series of children with specific developmental speech and related disorders (Hallgren, 1950). The high proportion of patients $(46.25 \%)$ with fathers in Social Classes I and II is striking, and probably reflects the greater attention paid by parents in these classes to retarded speech development rather than any greater prevalence of the disorders in the higher social classes. The prospects of their undergoing competitive entrance interviews in order to obtain a place in private schools often exacerbated parents' anxieties about their children's speech.

The majority of the children referred were under the age of 5 , as might be expected in view of the tendency for specific developmental disorders of speech to remit as the patient grows older. Only 
15 of the 80 patients were over the age of 5 , and in the majority of these the speech disorder, though a nuisance in school, had ceased to be a major cause of anxiety to the parents. The fact that only three of the patients were over the age of 7 illustrates that in the majority of patients speech is perfectly comprehensible by this age.

The distribution of children by their birth order was not significantly different from the expected random distribution. The fact that 43 of the 73 patients were last-born is unremarkable in view of their youth. Their parents had not had time to produce subsequent children, especially those staid middle-class Scots with planned families. Seven of the patients were illegitimate.

A family history of retarded speech development is often found in cases of specific developmental speech disorders. Thirty-seven of the 73 legitimate patients (about half) had parents or siblings whose speech development was known to have been slow. Since it was common on examination to find siblings with speech disorders who had been stated by the parents to be 'rare talkers' or 'lovely speakers', this is probably an under-estimate. Parents were known to have retarded speech development in 19 cases, and one or more siblings in 21.

Fifteen patients were born after pregnancies, labours or deliveries which were in some way abnormal, 11 of them being born prematurely by weight. No convincing evidence of birth injury was found in any of them, however, and neurological examination failed to reveal any clinical signs of cerebral injury.

Ambidexterity, as assessed by the tests which have been described, was noted in half of the 80 patients. Only one patient was strongly left-handed. Parents reported left-handedness or ambidexterity in themselves in 22 cases, and in the patients' siblings in 16 cases. Thus 38 , or approximately $52 \%$, of 73 legitimate patients had an immediate family history of sinistrality or ambidexterity.

Seven children had intelligence quotients of more than 120 on the Terman Merrill scale, and only two were considered to be dull and backward. It was interesting to observe, however, that specific educational difficulties (dysgraphia or dyslexia) were present in seven of the 15 patients over the age of 5 . In these cases it seemed legitimate to conclude that the children were having specific difficulties with the written word which might be related to the troubles they had previously had with the spoken word (Ingram and Reid, 1956; Drew, 1956).

Two forms of retarded development may be recognized in patients coming into this category. About half of the children are described by their parents as having 'names' for objects within their environment which are not intelligible to observing strangers at quite an early age, though they may be comprehensible to the patient's siblings and parents. Their vocabulary is often considerable, but their articulation of the words they know is so defective that they cannot be understood. Frequently the ends of words are much less well articulated than their beginnings. When the children begin to join words together the defects of articulation tend to become more prominent, and a frequent complaint from baffled mothers is that 'he says plenty ard he's anything but stupid, but I can understand only a few words of what he says'. In these patients the major diability is imperfect articulation. The development of language may not ke much retarded, but what the child says is so imperfectly spoken that much of it cannot be understood.

The articulatory difficulties of children with specific developmental speech disorders are complex, and at first hearing quite baffling when one tries to analyse them. The sounds most often poorly articulated are shown in Table 6. (It should be pointed out that this was the result of study by the author and by speech therapists, not that of properly trained phoneticians.) In general the sounds which are the last to be correctly articulated by normal children are the ones which cause most difficulty. They may be omitted, faultily pronounced, or substituted by other sounds. The substitutions employed vary with the context of the sound which is defective. Sounds are more often omitted or faultily articulated at the ends than at the beginnings or middle portions of words, and more frequently at the beginnings than the middles. It is characteristic that words which the child has had in his vocabulary for a long time are articulated with more faults than words more recently acquired. Thus a child may say 'goggie' for 'doggie', 'wa-wa' for 'water' and 'ba' for 'bath', but be able to say 'Dalgleish', 'wetter' and 'with' quite well. That the articulatory difficulties appear to be so inconsistent often leads parents to accuse their children of laziness. Their observation that many patients can produce sounds correctly on request, which are abnormal in spontaneous speech, further infuriates them.

About half of the patients in the category have language difficulties. They are slow in acquiring new words and often the rate of vocabulary gain is so poor that they have to use gestures to indicate their simplest needs until the age of 3 years or older. When sentences are eventually formed, inversion of word order, omission of consonants, prepositions, auxiliary verbs and some personal pronouns are commonly noted. Many of these children will use, 
quite unwittingly, a completely inappropriate word in a sentence in place of a similarly sounding one which would have been appropriate. They suffer from classical 'developmental aphasia' (Orton, 1937).

Of the 80 patients suffering from developmental speech disorders in the present series, 40 had obvious language (aphasic) difficulties of the type which has been described, and in the other 40 the speech defect appeared to be predominantly of articulation and did not affect the development of language so severely.

Difficulty in comprehending what was said to them was frequently observed in children suffering from specific developmental speech disorders. In severe cases the child's inability to understand what is said is severe enough to make the parents suspect deafness, though they will often give circumstantial accounts of why they think this unlikely; for example, "he hears the whistle of the television set when it goes off, and looks up at aeroplanes'. In less severe cases parents were often irritated by the child's tendency to demand repetition of everything which was said to him by saying 'Eh', 'Beg pardon', 'What', or the child would look blank. Mothers and fathers would often complain of their partner's tendency to gesture to the child, though they are unaware of their own tendency to do so. On examination a distinct lapse of time may be observed before the child comprehends what is said to him, though his reactions when he has understood are often intelligent. The tendency of some patients to look at faces and rely on gesture rather than on speech is frequently evident.

In the present series 30 patients appeared to have comprehension difficulties of this type. In 23 they were associated with marked retardation of language development, and language difficulties characteristic of developmental aphasia were observed on examinaapparent at the time of examination. In general, children with obvious difficulties in comprehension had the most retarded development of speech and tion. In seven language difficulties were not

the most severe defects of articulation and language, as is seen in Table 5 .

TABLE 5

SPEECH DEVELOPMENT OF 80 CHILDREN SUFFERING FROM SPECIFIC DEVELOPMENTAL SPEECH DISORDERS $\dagger$

\begin{tabular}{|c|c|c|c|c|c|}
\hline \multirow[b]{2}{*}{ Speech Development } & \multirow[b]{2}{*}{ Total } & \multicolumn{2}{|c|}{$\begin{array}{l}\text { Receptive } \\
\text { Difficulty }\end{array}$} & \multicolumn{2}{|c|}{$\begin{array}{l}\text { Language } \\
\text { Difficulty }\end{array}$} \\
\hline & & With & Without & With & Without \\
\hline $\begin{array}{l}\text { Words before } 18 \text { mth. } \\
\text { and phrases before } 30 \\
\text { mth. } . .\end{array}$ & 21 & 5 & 16 & 4 & 17 \\
\hline $\begin{array}{l}\text { Words before } 18 \mathrm{mth} . \\
\text { and phrases after } 30 \\
\text { mth. } \quad . .\end{array}$ & & & & & \\
\hline $\begin{array}{l}\text { Words after } 18 \mathrm{mth} \\
\text { and phrases before } 30 \\
\text { mth. }\end{array}$ & 10 & 4 & 6 & 7 & 3 \\
\hline 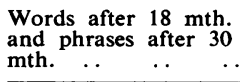 & $49 *$ & 21 & 28 & 29 & 20 \\
\hline Total & 80 & 30 & 50 & 40 & 40 \\
\hline
\end{tabular}

* Of these 49 children $\left\{\begin{array}{l}\text { words came after } 24 \mathrm{mth} . \\ \text { and phrases after } 36 \mathrm{mth} .\end{array}\right\}$ in 22 cases.

$\dagger$ All but nine children walked before 18 months.

TABLE 6

MOST FREQUENTLY MISPRONOUNCED, SUBSTITUTED OR OMITTED SOUNDS IN 80 CHILDREN, WITH SPECIFIC DEVELOPMENTAL SPEECH DISORDERS

\begin{tabular}{|c|c|c|}
\hline Sounds & $\begin{array}{c}\text { Group } 1^{*} \\
\text { \% with } \\
\text { defective sounds }\end{array}$ & $\begin{array}{c}\text { Group } 2 \dagger \\
\% \text { with } \\
\text { defective sounds }\end{array}$ \\
\hline $\begin{array}{l}\mathbf{r} \text { (sh) } \\
\int_{\theta} \text { (thing) } \\
\mathbf{s} \\
1 \\
\mathrm{k} \\
\int_{\mathrm{f}}(\text { church) } \\
\mathrm{d} 3 \text { (hedge) } \\
\mathbf{g} \\
\mathbf{f} \\
\mathrm{v} \\
\mathrm{p} \\
\mathrm{b}\end{array}$ & $\begin{array}{l}78 \\
74 \\
66 \\
63 \\
62 \\
36 \\
34 \\
34 \\
26 \\
20 \\
17 \\
17 \\
17\end{array}$ & $\begin{array}{r}37 \\
15 \\
31 \\
5 \\
1 \\
12 \\
13 \\
13 \\
9 \\
6 \\
- \\
1 \\
-\end{array}$ \\
\hline
\end{tabular}

TABLE 7

LOCAL ABNORMALITIES OF THE ARTICULATORY APPARATUS IN 80 PATIENTS WITH SPECIFIC DEVELOPMENTAL SPEECH DISORDERS

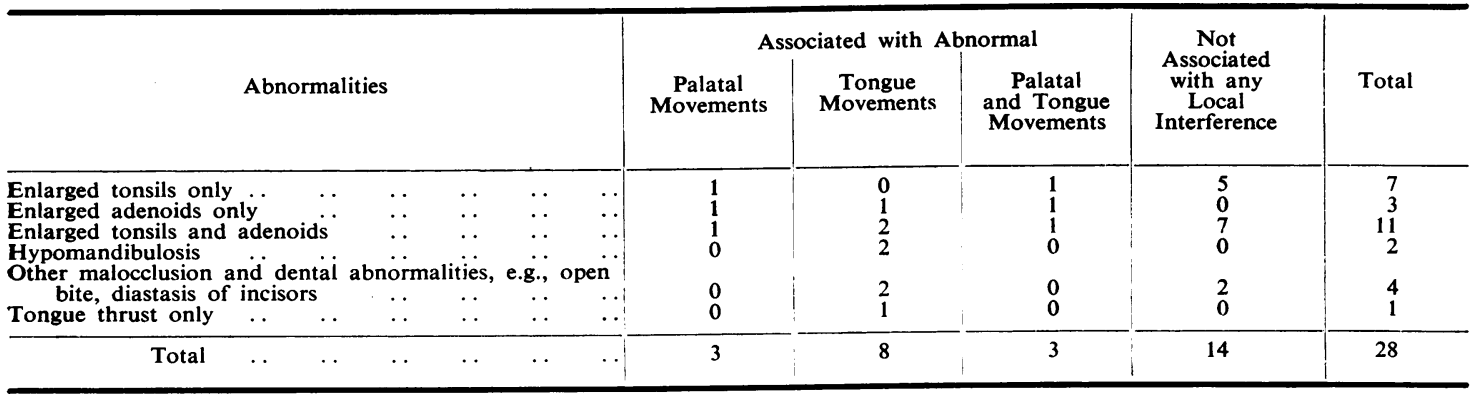


Frequently minor abnormalities of the articulatory apparatus are observed in patients with specific developmental speech disorders. Those found in the present series are shown in Table 7. In many patients (14 of the 28 with local abnormalities) no interference with the function of the articulatory organs could be demonstrated. In the remainder it required only a rudimentary knowledge of phonetics to realize that the local abnormalities could not be held responsible for the complex speech disturbance, often affecting language as well as articulation of a wide variety of sounds.

Abnormalities of behaviour are frequent in patients with specific developmental speech disorders. In the majority of cases they appear to be secondary to the speech defect. Obviously the situation in which an intelligent child with a speech defect often finds himself is stressful. He is deprived of the means to communicate his ideas, frequently in social circumstances where much attention is paid to language and articulation. Later on specific educational difficulties may also be present.

His reactions to this situation may be by withdrawal. Solitariness, inability to play with other children, day-dreaming, excessive dependence on the mother, and fearfulness were complained of in 18 of the patients. Four others seemed unusually tense, excitable and tearful. Four reacted to frustration by severe temper tantrums. Three (over the age of 4 years) were enuretic.

Mixed Cases and Unclassified Cases. In a classification whose categories are defined in terms of the single major speech disability it is inevitable that a small number of patients with multiple defects could fall into more than one of the major categories. Provision is made for them by having a category for 'mixed cases'. There were only four such patients in the present series. They included one child with severe hypomandibulosis, cerebral diplegia causing impaired voluntary movement of the articulatory organs and mental defect. Another had a cleft palate and suffered from nerve deafness following tuberculous meningitis.

A few patients resist classification even after full investigation and they are provided for in the category of 'other and unclassified cases'. This category may be compared to a basket of correspondence marked 'pending', from which cases will be taken and placed in other categories when more accurately diagnosed.

\section{Discussion}

That there is a need for an adequate description of speech disorders in childhood cannot be doubted by anyone who has to deal with children suffering from speech defects, or by anyone acquainted with the currently accepted literature on the subject (Seth and Guthrie, 1935; Van Riper, 1947). Unfortunately the amount of clinical investigation devoted to disorders of children's speech has been relatively small. Much of it has been the result of speech therapists, phoneticians, linguists, otologists, neurologists or psychologists working in isolation. Yet the problems of accurate diagnosis cannot be solved by a lone worker from one of these disciplines, however expert he may be. Classification based on the clinical findings which seem to be important to a worker in any one of these sciences is bound to be inadequate for other workers with differing points of view.

The benefits of a team approach to speech problems in childhood have not been sufficiently realized, though the work of Miss Muriel Morley and her colleagues shows that it may be rewarding (Morley, Court and Miller, 1950; Morley, Court and Miller, 1954; Morley, Court, Miller and Garside, 1955; Morley, 1957). Their pioneer descriptions and classification of speech defects in childhood mark a significant advance on previous work and deserve close study and criticism (Table 8).

TABLE 8

CLASSIFICATION OF SPEECH DEFECTS IN CHILDHOOD BY MORLEY (1957)

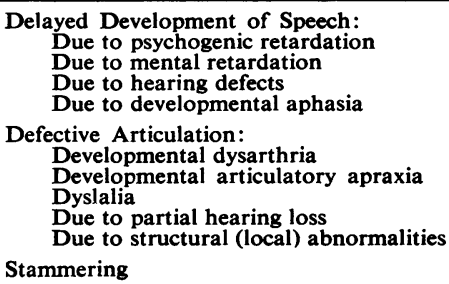

It will be seen that an attempt is made to distinguish between 'delayed development of speech' and 'defective articulation' as major categories. Unfortunately this ignores the fact that a high proportion of patients with 'delayed development of speech' have defective articulation, and a significant number with 'defective articulation' have retarded speech development.

The definition of a number of the sub-categories is unsatisfactory, and sometimes misleading. Thus 72 of her 74 patients considered to suffer from 'developmental aphasia' are regarded as suffering from 'executive aphasia' because they showed no difficulty in comprehending speech at the time of examination, though their speech development was retarded. The term 'executive aphasia' has a very 
specific meaning in adult neurology. It is misused when it is applied to children with retardation of language development merely because they have no obvious difficulties of comprehension. If speech were merely the issuing through the mouth of sequences of sounds which had been poured into the child's ear, as if through a pipeline, there might be some justification for using the term in this way. But the processes involved in the perception, comprehension and utterance of speech are incredibly complicated and still poorly understood. To assume that a child suffers from 'executive' or even 'expressive aphasia' because the end result of this process is defective, though the child appears to comprehend speech, is an unjustified simplification of an extremely complicated problem.

The term 'developmental articulatory apraxia' is open to severe criticism. It implies that appreciation of the movements made by the articulatory organs during speech is so defective that accurate articulation is impossible. Yet it is usually impossible to demonstrate any abnormality of movement on examination, as the author admits. The assumption she makes that apraxia is troublesome only with fine movements required by speech is more ingenious than convincing. The use of the term 'apraxia', a descriptive neurological term, is probably best avoided until means of testing for apraxia of tongue, lips and palate during speech are available.

The fact that five of 12 children with 'developmental articulatory apraxia' who were closely studied by Morley and her colleagues had 'some delay in the first use of words; and phrases were not attempted before 4 years', suggested similarities to histories of patients she classifies as suffering from 'developmental aphasia'. Nine of the 15 children with 'developmental aphasia' had 'defective articulation'. There seems to be a good case for grouping together patients with these two conditions into a single major category of 'specific developmental speech disorders', in which retardation of the development of language and articulation are the major characteristics. This suggestion is followed in the present classification.

It will be noted that the classification dispenses with the category of 'dyslalia' which occurs in Miss Morley's classification. The term dyslalia is used very indiscriminately by clinicians to refer to a wide variety of speech disorders in childhood. Even Morley (1957) does not provide a satisfactory definition though most of the patients she includes in the category appear to suffer from transient, usually mild, disorders of articulation not associated with obvious abnormalities of the movements of the articulatory organs or with retardation of speech development. She suggests that 'dyslalia' may be associated with mental defect, 'environmental and psychogenic factors', and imitation or persistence of faulty patterns of articulation. Many of the cases in this category could obviously be placed in other of her categories. In view of this and the wide misuse of the term dyslalia, it has been thought best to discard it.

The term 'developmental dysarthria' is misleading. The adjective 'developmental' implies that the disorder will disappear or be very much ameliorated with maturation. Yet many of the patients in the category of 'developmental dysarthria' suffer from cerebral palsy and other neurological abnormalities. In them the improvement in speech tends to be extremely disappointing, especially after the age of 5 or 6 years. In this sense their speech disorders cannot be regarded as being 'developmental'.

The aim in the present classification has been to define the categories of children's speech disorders in terms of the major abnormality of speech which is present, and by the child's associated clinical and psychological abnormalities. Clearly such a classification requires that patients shall be fully studied from a number of different points of view. This requires a team approach in modern conditions, similar to that used in cerebral palsy and child guidance clinics. If such a team approach cannot be adopted, accuracy of diagnosis of speech defects suffers, and the classification accordingly becomes less useful.

\section{Summary}

Descriptions of the commoner defects of speech encountered in a hospital speech clinic largely devoted to the treatment of pre-school children have been presented.

A new classification of speech disorders in childhood based on the major defect of speech and on associated clinical and psychological findings is given. It is emphasized that accurate diagnosis and classification of speech defects requires a team consisting of speech therapist, psychologist, paediatrician and otologist. The help of a social worker, neurologist, phonetician, child psychiatrist and other hospital staff may be required in both diagnosis and treatment.

Criticisms are made of the classification of speech defects proposed by Morley (1957) on the grounds of the imprecise use of a few neurological terms and the lack of clear definition of some of the categories proposed, in terms of clinical findings.

I have to thank Miss Morrison, Speech Therapist to the Royal Hospital for Sick Children, Edinburgh, and her assistants for their co-operation and interest during 
the investigation. I am indebted to Miss Mason, lately of the Psychology Department, University of Edinburgh, and Miss Mary Waller for the psychological examinations, Miss Sylvia Massey of the Department of Psychological Medicine for her psychiatric social reports, and Dr. Margaret Methven of the same Department for her consistent co-operation and help. Dr. Werner Schutt examined many of the patients from the paediatric point of view. I must thank Professor R. W. B. Ellis for his stimulus and encouragement of this work, and the physicians and surgeons of the Royal Hospital for Sick Children for their interest and co-operation during it. I am grateful to Mr. Ian Catford, Director of the School of Applied Linguistics, University of Edinburgh, who was good enough to criticize this paper.

\section{REFERENCES}

Birrell, J. F. (1954). Speech, 18, 40.

Calnan, J. (1957). Ibid., 21, 59.

Critchley, M. (1952). J. Laryng., 66, 1.

Drew, A. L. (1956). Brain, 79, 440.

Evans. P. R. (1955). Archives of Disease in Childhood, 30, 237.

Francis, T. R. (1958). Speech Path. and Therapy, 1, 70.
Gibb, A. G. (1958). J. Laryng., 72, 433.

Hallgren, B. (1950). Acta psychiat. scand., Suppl. 65.

Henderson, J. L. (1939). Brain, 62, 381

Ingram, T. T. S. (1956). J ment. Sci. 102, 550.

Ingram, T. T. S. (1956) J. ment. Sci., 102, 550 . 161 .

Johnson, W., Brown, S. F., Curtis, J. F. Edney, C. W. and Keaster, J. (1948). Speech Handicapped School Children. Harper, New York.

Monrad-Krohn, G. H. (1947). Acta psychiat. scand., Suppl. 46, 204.

Morley, M. E. (1954). Cleft Palate and Speech, 3rd ed. Livingstone,

Edinburgh.
(1957). The Development and Disorders of Speech in Childhood. (1957). The Development
Livingstone, Edinburgh.

Court, D. and Miller, H. (1950). Brit. med. J., 1, 574.

- - (1954). Ibid., 1, 8 .

,-- and Garside, R. F. (1955). Ibid., 2, 463.

Orton, S. T. (1937). Reading, Writing and Speech Problems in Children Chapman and Hall, London.

Ounsted, C. (1955). Lancet, 2, 303.

Registrar General for Scotland (1951). Ninety-seventh Annual Report. H.M.S.O.

Seth, G. and Guthrie, D. (1935). Speech in Childhood: Its Development and Disorders. Oxford University Press, London.

Travis, L. E. (1931). Speech Pathology. Appleton, New York.

Van Riper, C. (1947) Speech Correction-Principles and Methods, 2nd ed. Prentice-Hall, New York.

Wilson, S. A. Kinnier (1954). Neurology, 2nd ed. Edited by A. N Bruce. Butterworth, London. 